\title{
Different expression levels of interleukin-35 in asthma phenotypes
}

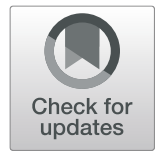

Wei Li', Ruihan Gao ${ }^{2}$, Tong Xin ${ }^{3}$ and Peng Gao ${ }^{1 *}$

\begin{abstract}
Background: Interleukin (IL)-35 is a newly discovered inhibitory cytokine which is produced by regulatory B and T lymphocytes and belongs to the IL-12 family. It plays a suppressive role in human inflammatory diseases; however, its role in asthma phenotypes is unclear. Our study focuses on the sputum IL-35 level in patients and investigates different airway inflammation capacities of sputum IL-35 in patients with different asthma phenotypes.

Objective: We aimed to determine the sputum IL-35 levels in asthmatic patients with clinical remission phenotypes and control subjects and to investigate possible correlations among lung function, age, sex, fractional exhaled nitric oxide (FeNO), and smoking history in these phenotypes.

Methods: Sputum samples were collected from patients with clinical asthma remission ( $n=89,37$ males, age $52.24 \pm 13.32$ years) and a healthy control group ( $n=19,9$ males, age $44.58 \pm 16.3$ years). All subjects underwent sputum induction. Induced sputum was assessed for inflammatory cell count, and sputum levels of IL-35 and other cytokines were measured by ELISA and Cytometric Bead Array, respectively.

Results: Sputum IL-35 (median (q1, q3)) levels showed no significant difference between asthma patients (4.89 ng/ $\mathrm{mL}(2.97,22.75))$ and healthy controls $(6.01 \mathrm{ng} / \mathrm{mL}(4.09,30.47))$. However, the sputum IL-35 level was significantly reduced in patients with eosinophilic asthma (EA) $(3.95 \mathrm{ng} / \mathrm{mL}(2.80,11.00))$ compared to patients with neutrophilic asthma (NA) $(40.59 \mathrm{ng} / \mathrm{mL}(20.59,65.06), p=0.002)$, paucigranulocytic asthma (PA) $(6.25 \mathrm{ng} / \mathrm{mL}(3.10,24.60), p=$ $0.012)$, and mixed granulocytic asthma (MA) $(22.54 \mathrm{ng} / \mathrm{mL}(2.58,52.45), p=0.026)$. IL-35 levels in sputum showed a positive correlation with sputum neutrophil cells and a negative correlation with FeNO, FEV1\% predicted, and FVC predicted. Furthermore, sputum IL-35 had a significant positive association with Th1-related factors and a negative correlation with Th2-related factors.
\end{abstract}

Conclusions: Sputum IL-35 is likely involved in different pathophysiological mechanisms of NA and EA and exerts different effects in asthma phenotypes.

Keywords: Asthma, IL-35, Induced sputum, Neutrophils, Eosinophils

\section{Background}

Over a 25-year period, from 1990 to 2015, the prevalence of asthma increased by $12.6 \%$; and in 2015, a total of 358.2 million people suffered from asthma, including 168 million men and 190.2 million women [1]. Asthma

\footnotetext{
* Correspondence: gaopeng1234@sina.com

'Department of Respiratory and Critical Care Medicine, The Second Hospital of Jilin University, Changchun, Jilin 130041, China

Full list of author information is available at the end of the article
}

is one of the most common types of bronchial inflammation in respiratory diseases and is clinically characterized by reversible bronchoconstriction and airway hyperresponsiveness (AHR) [2, 3]. Airway inflammation is usually thought to be caused by the Th2 immune response or eosinophil participation, which is a pathogenetic marker of bronchial asthma. However, some patients show neutrophil dominance, have low (or even non-existent) Th2 cytokines, and exhibit a poor response

(c) The Author(s). 2020 Open Access This article is licensed under a Creative Commons Attribution 4.0 International License, which permits use, sharing, adaptation, distribution and reproduction in any medium or format, as long as you give appropriate credit to the original author(s) and the source, provide a link to the Creative Commons licence, and indicate if changes were made. The images or other third party material in this article are included in the article's Creative Commons licence, unless indicated otherwise in a credit line to the material. If material is not included in the article's Creative Commons licence and your intended use is not permitted by statutory regulation or exceeds the permitted use, you will need to obtain permission directly from the copyright holder. To view a copy of this licence, visit http://creativecommons.org/licenses/by/4.0/ The Creative Commons Public Domain Dedication waiver (http://creativecommons.org/publicdomain/zero/1.0/) applies to the data made available in this article, unless otherwise stated in a credit line to the data. 
to inhaled corticosteroids $[4,5]$. Depending on the type of inflammatory cells present in sputum, asthma can be classified into the following four phenotypes: eosinophilic asthma (EA), neutrophilic asthma (NA), mixed granulocytic asthma (MA), and paucigranulocytic asthma (PA) [6]. In recent years, many studies have shown that each phenotype has a different mechanism of action and a different response to treatment. In EA, biomarkers such as eosinophils [7], periostin, fractional exhaled nitric oxide (FeNO), and IgE [8] can predict corticosteroid reactivity. But for non-eosinophilic asthma, particularly NA, further research on possible biomarkers and treatment strategies is needed $[9,10]$.

Interleukin (IL)-35 is a newly discovered member of the IL-12 family, which is a heterodimer composed of the p35 and Ebi3 components, and is produced by a variety of cell types and tissues, including T-cells, B-cells, Tregs, monocytes and resting tumor cells $[11,12]$. Unlike other IL-12 family members, IL-35 has important inhibitory properties [13, 14]. IL-35 may alter the immune response by inducing proliferation of regulatory T-cells and promoting differentiation of Th17 cells. The cytokines released by Th17 cells induce airway epithelial cells to release chemokines that attract neutrophils. In addition, IL-35 reduces the development of Th2 cells and the production of Th2 cytokines that elevate allergen-specific Th2 responses and allergic airway diseases [15]. In the ovalbumin (OVA)-induced mouse asthma model, treatment with recombinant IL-35 or adenovirus-mediated IL-35 inhibited the extent of AHR and allergic inflammation [15]. Nevertheless, the role of IL-35 in asthma is still controversial. Wong and colleagues found that patients with asthma have higher levels of IL-35 than normal subjects and that higher levels of IL-35 are positively correlated with asthma severity [16]. However, Wang et al. found reduced levels of circulating IL-35 in asthmatic patients and that decreased IL-35 levels increase the number of CD8+ Tcells that produce IL-4 [17].

We hypothesized that the heterogeneity of asthma could lead to different experimental results, as described above. Thus, in this study, we compared the sputum concentration of IL-35 in patients with different asthma phenotypes and investigated the relationship between IL-35 and asthma phenotypes.

\section{Methods}

\section{Study population}

Asthma diagnosis was established according to the guidelines from the American Thoracic Society and was based on current episodic respiratory symptoms (over the past 12 months), clinical diagnosis, and evidence of variable airflow obstruction [18]. Patients were in a stable phase of the disease without taking oral corticosteroids or antibiotics, and there was an absence of worsening of asthma symptoms and treatment changes over the 4 weeks leading up to this assessment.

Matched healthy Chinese volunteers were recruited as normal controls. All control subjects were screened using a questionnaire and a simple physical examination to ensure that they did not show any abnormal signs or history of asthma or other autoimmune diseases.

All study subjects received a written assessment of their clinical evaluation, which included smoking history, respiratory symptoms, and sputum induction. Ethical approval was received from the Ethics Committee of the Second Hospital of Jilin University with the approval number 2014-003.

Exclusion criteria for this study were as follows: pregnant women, severe cardiovascular and cerebrovascular diseases, malignant tumors of various systems and organs, chronic diseases of various systems and organs, active tuberculosis, and interstitial lung diseases.

\section{Sputum collection}

Sputum induction and processing was performed as described in previously published articles [19]. In brief, sputum induction time with hypertonic saline (4.5\%) was fixed at $15 \mathrm{~min}$ for all participants. For the inflammatory cell count, sputum cells were dispersed using dithiothreitol (DTT), and were resuspended in phosphate buffered saline (PBS, pH 7.4). The suspension $(60 \mu \mathrm{m}$, Haimen Chunbo Biological Experimental Equipment Factory, China) was then filtered and the total cell count, which included leukocytes and columnar epithelial cells (inflammatory cell count $\times 0.02$ /quadrant, TCC), and cell viability (viable cell count/total cell count) were assessed. A cytospin smear was prepared and stained (May-Grunwald Giemsa), and a total of 400 non-squamous cells were counted to classify differential inflammatory cells. The quality of induced sputum samples was assessed; less than $50 \%$ of squamous epithelial cells and more than $40 \%$ of cell viability were considered significant. The sputum supernatant was stored in a microcentrifuge tube at $-80^{\circ} \mathrm{C}$ for subsequent testing.

\section{Measurement of IL-35 and other cytokines}

Quantitative detection of sputum IL-35 was performed using the commercial human interleukin-35 (IL-35) ELISA kit (Catalog Number CSB-E13126h, CUSABIO, China) in accordance with the manufacturer's protocol. The levels of other cytokines (IL-1 $\beta$, IL-6, IL-8, IL-10, IL-17A, IL-23, TNF- $\alpha$, and MCP-1) were measured by Cytometric Bead Array (CBA) under the Multi-Analyte Flow Assay Kit (Biolegend, United States) according to the manufacturer's instructions. All incubation steps were performed at room temperature and away from the light. Capture beads $(75 \mu \mathrm{L})$ were added to each titertube 
and incubated for 2 hours. Then, an antibody detection reagent $(25 \mu \mathrm{L})$ was added to each titertube, mixed, and incubated for $1 \mathrm{~h}$. The Streptavidin-R-phycoerythrin (SA-PE) detection reagent $(25 \mu \mathrm{L})$ was then added to each titertube, mixed, and incubated for $30 \mathrm{~min}$. Each titertube was then loaded into a BD LSRFortessa flow cytometer, and a total of 300 events per target were recorded per well. The data were analyzed using the LEGENDplex v8.0 software. IL4 and IL5 were assayed but more than half of the samples were below the lower limit of detection for all sputum inflammation groups (data not shown).

\section{Asthma phenotype classification}

The granulocyte cut-off value of sputum eosinophils was $3 \%$, and the cut-off value of sputum neutrophils was $61 \%$ [20]. The patients were divided into EA with sputum eosinophils $\geq 3 \%$, NA with neutrophils $\geq 61 \%$, PA with eosinophils $<3 \%$ and neutrophils $<61 \%$, and MA with eosinophils $\geq 3 \%$ and neutrophils $\geq 61 \%$.

\section{Statistical analysis}

All analyses were conducted using Windows Statistical Package for the Social Sciences (SPSS) statistical software, Version 20 (SPSS Inc., IL, USA). Normally distributed data are expressed as the mean \pm standard deviation (SD) and were compared using an ANOVA with a least significant difference (LSD) or Student's t-test. Logarithmic transformation was performed for all levels of inflammatory mediators, and then the normal distribution was examined and analyzed using the variance with an LSD post hoc test. Nonparametric data are reported as the median and interquartile range (IQR) and were analyzed with a Kruskal-Wallis test followed by Bonferroni correction or a Mann-Whitney U test for post hoc analysis. Spearman's rank correlation coefficient was used to test the correlation and was adjusted for age and BMI. Categorical variables were analyzed using a Chi-squared test. A $p$ value of $<0.05$ was considered statistically significant.

\section{Results}

\section{Clinical characteristics of asthma patients and healthy} volunteers

There were 89 asthma patients with an average age of 52 years (Table 1 ). The sputum cell count was available for all asthma patients, and they were all assigned an inflammatory phenotype. Accordingly, 38 (42.7\%) asthma patients had EA, 38 (42.7\%) had PA, 4 (4.5\%) had NA, and 9 (10.1\%) had MA.

There was no significant difference in gender, body mass index, or smoking index between the asthma group and the healthy control group $(P>0.05)$, but the age of asthma patients was significantly higher than that of
Table 1 Characteristics of patients and healthy controls

\begin{tabular}{llll}
\hline Variable & Asthma & Normal & $P$ value \\
\hline Number & 89 & 19 & \\
Age (years) & $52.24 \pm 13.32$ & $44.58 \pm 16.30$ & 0.025 \\
Sex, male (\%) & $37(41.6)$ & $9(47.4)$ & 0.617 \\
BMI $\left(\mathrm{kg} / \mathrm{m}^{2}\right)$ & $23.86 \pm 3.49$ & $23.22 \pm 3.28$ & 0.589 \\
Ex-smoker, n (\%) & $23(25.8)$ & $7(36.84)$ & 0.667 \\
Smoking index & $0(0,15)$ & $0(0,5.25)$ & 0.796 \\
Post-FEV1 $(\mathrm{L})$ & $2.36 \pm 1.00$ & $3.13 \pm 0.91$ & 0.009 \\
Post-FVC $(\mathrm{L})$ & $3.53 \pm 1.20$ & $3.65 \pm 0.79$ & 0.677 \\
FeNO $(\mathrm{ppd})$ & $42.20(27.80,99.65)$ & $22.5(16.5,24.00)$ & 0.004 \\
Sputum TCC $\left(10^{6} / \mathrm{mL}\right)$ & $3.00(1.80,5.40)$ & $2.43(1.62,3.24)$ & 0.180 \\
Sputum NEU $\left(10^{4} / \mathrm{mL}\right)$ & $10(1,91)$ & $0(0,6)$ & $<0.001$ \\
Sputum EOS $\left(10^{4} / \mathrm{mL}\right)$ & $7(0,58)$ & $0(0,2)$ & $<0.001$ \\
Sputum MA $\left(10^{6} / \mathrm{mL}\right)$ & $1.34(0.27,3.52)$ & $2.37(1.56,3.12)$ & 0.100 \\
Sputum LY $\left(10^{4} / \mathrm{mL}\right)$ & $2.51(0,16.46)$ & $5.49(1.08,12.96)$ & 0.255
\end{tabular}

Data are expressed as mean \pm SD or median (IQR). Data were analyzed using a Student's t-test or a Mann-Whitney $\mathrm{U}$ test and were adjusted for age. BMI Body mass index, FEV1 Forced expiratory volume in $1 \mathrm{~s}$, FVC Forced vital capacity, FeNO Fractional exhaled nitric oxide, TCC Total cell count, NEU Neutrophils, EOS Eosinophils, MA Macrophages, LY: Lymphocyte

healthy controls $(P=0.025)$. The Post-FEV1 in the asthma group was significantly lower than that in the healthy control group $(P=0.009)$. There was a significant increase in FeNO in the asthma group compared with the healthy control group $(P=0.004)$. Compared with the healthy control group, the number of eosinophils and neutrophils was significantly higher in the asthma group (eosinophils: $P<0.001$, neutrophils: $P<0.001$ ) (Table 1). The IL-35 level in the asthma group was lower than that in the healthy control group, but the difference was not statistically significant $(P=$ 0.247). IL1 $\beta$ and IL8 were also lower in the asthmatic group compared to the normal control group but not at the level of statistical significance. The levels of IL- 6 and MCP-1 in the asthma group were significantly higher than those in the healthy control group (IL-6: $P=0.013$, MCP-1: $P=0.003)$, while IL-17A showed an opposite trend $(P<0.001)$ (Table 2).

\section{Clinical features of inflammatory phenotypes in asthma} Gender, BMI, and smoking history were similar among the four asthma subgroups (Table 3). Compared to the other groups, the PA group showed the best lung function, while the EA group was the youngest (Table 3).

\section{IL-35 and other inflammatory mediators in asthma inflammatory phenotypes}

Compared with the PA and MA groups, the sputum IL35 level was significantly decreased in the EA group and significantly increased in the NA group. Patients with MA had significantly increased concentrations of 
Table 2 Sputum chemokine concentrations in asthma patients and healthy controls

\begin{tabular}{|c|c|c|c|}
\hline Variable & Asthma & Normal & $P$ value \\
\hline Number & 89 & 19 & \\
\hline $\mathrm{IL}-1 \beta(\mathrm{pg} / \mathrm{ml})$ & $37.53(10.59,151.78)$ & $38.44(15.7,72.94)$ & 0.811 \\
\hline IL-6 (pg/ml) & $9.43(3.44,40.61)$ & $4.36(2.95,13.36)$ & 0.013 \\
\hline IL-8 (pg/ml) & $3099.66(278.93,8805.46)$ & $3428.69(612.39,12,145.63)$ & 0.164 \\
\hline IL-10 (pg/ml) & $0.78(0.54,1.36)$ & $1.35(0.92,1.61)$ & 0.052 \\
\hline IL-17A (pg/ml) & $6.16(1.10,15.09)$ & $53.95(18.02,81.59)$ & $<0.001$ \\
\hline IL-23 (pg/ml) & $8.10(3.57,20.99)$ & $19.33(8.63,38.75)$ & 0.034 \\
\hline TNF-a (pg/ml) & $0.49(0.32,0.79)$ & $0.46(0.34,0.67)$ & 0.404 \\
\hline IL-35 (ng/ml) & $4.89(2.97,22.75)$ & $6.01(4.09,30.47)$ & 0.247 \\
\hline MCP-1 (pg/ml) & $118.20(17.87,280.02)$ & $25.45(3.25,70.32)$ & 0.003 \\
\hline
\end{tabular}

Data are expressed as median (IQR). Data were analyzed using a Mann-Whitney $\mathrm{U}$ test and adjusted for age. IL Interleukin, TNF Tumor necrosis factor, MCP monocyte chemoattractant protein

sputum IL-1 $\beta$, IL-8, IL-10, IL-17A, IL-23, and TNF- $\alpha$ compared to those in the other groups. Also, the level of IL-6 was significantly higher in the MA group compared with the EA group, but there was no difference among the other asthma inflammatory phenotypes. The sputum MCP-1 level did not differ among the asthma phenotypes, but the level in the MA group was significantly higher than that in the other groups (Fig. 1).

\section{Association between inflammatory mediators and clinical characteristics}

Sputum IL-35 was negatively correlated with FeNO (ppd), FEV1 (\%), and FVC (\%) (Fig. 2). Sputum IL-35 was positively correlated with the number of neutrophils (Fig. 2). Sputum IL-35 had a significant positive association with IL-6, IL-8, IL-23, IL-1 $\beta$ and TNF- $\alpha$ (Supplementary Table 1 ).

\section{Effect of inhaled corticosteroid (ICS)}

We compared the levels of sputum inflammatory mediators in patients taking different doses of ICS. The level of sputum IL-35 was the highest in patients who took a high dose of ICS. However, there was no difference in any of the other mediators between patients who took high-dose ICS and patients who took lower-dose ICS (Table 4).

\section{Discussion}

Our results show that the sputum concentrations of IL35 are lower in asthmatics than in healthy controls, which support the results of a previous experiment on IL-35 plasma concentration [26] and a study in children [27]. However, another study evaluated the plasma concentrations of IL-35 by ELISA and found that the IL-35 level in patients with allergic asthma was significantly higher than that in patients with non-allergic asthma [16]. Therefore, we wondered if there was any difference in the sputum IL-35 level in asthma patients or if these dissimilar results can be explained by the heterogeneity of asthma airway inflammation or differences in asthma phenotypes. To address this, we further assessed the different levels of sputum IL-35 in asthma phenotypes. Interestingly, a significantly increased level of IL-35 was found in patients with NA, while a significantly decreased level of IL-35 was noted in patients with EA, compared to patients with other phenotypes. Furthermore, there was a negative correlation between IL-35 and FEV1\%, FeNO and a positive correlation between IL-35 and the number of neutrophils and IL-1-related (IL-1 $\beta, 6$, and 8) inflammatory mediators. These findings suggest that IL-35 may play a key role in the infiltration and activity of eosinophils [28] and neutrophils [29] in asthma and may participate in the airway inflammation mechanism of asthma phenotypes.

The function of IL-35 is complex and the results of different studies may be contradictory. IL-35 has a proinflammatory effect in certain diseases, such as rheumatoid arthritis [30, 31] and Lyme arthritis [32], and has an anti-inflammatory effect in other diseases, such as liver inflammation [33], lung inflammation [34], airway inflammation [35], acquired aplastic anemia [36], atherosclerosis [37], arthritis [38], and colitis [39]. IL-35 also exerts different inflammatory effects in different models of the same disease. For instance, the level of IL-35 is significantly increased in collagen-induced arthritis (CIA) animal models showing arthritis symptoms but is reduced in the animal model of arthritis caused by Borrelia burgdorferi [32, 40]. In our research, the level of sputum IL-35 was measured in inflammatory asthma phenotypes and compared with the results of other asthma research. Wong et al. assessed the plasma concentration of IL-35 using ELISA and found that patients with allergic asthma had significantly higher levels of IL35 than those with non-allergic asthma. Plasma IL-35 
Table 3 Clinical characteristics and sputum cell numbers in asthma inflammatory phenotypes

\begin{tabular}{|c|c|c|c|c|c|}
\hline Variable & EA & NA & MA & PA & $P$ value \\
\hline Number & 38 & 4 & 9 & 38 & \\
\hline Age (years) & $47.08 \pm 13.54^{\Delta} ※$ & $64.25 \pm 6.75$ & $56.22 \pm 11.92^{\S}$ & $55.18 \pm 12.18^{\S}$ & 0.007 \\
\hline Male (\%) & 15 (39.5) & $1(25.0)$ & $4(44.4)$ & $17(44.7)$ & 0.899 \\
\hline BMI (kg/m2) & $23.97 \pm 3.20$ & $22.44 \pm 3.02$ & $25.77 \pm 3.74$ & $23.44 \pm 3.70$ & 0.271 \\
\hline $\mathrm{ACQ}+[21]$ & $2.0(2.0,3.0)$ & $1.5(1.0,2.0)$ & $2.0(0.3,2.8)$ & $2.0(1.0,2.0)$ & 0.930 \\
\hline $\mathrm{ACT}+[22]$ & $15(12,18)$ & $17.5(5.5,19.0)$ & $18(12,22.5)$ & $17(13,21.75)$ & 0.222 \\
\hline AQLQ† [23] & $4(4,5)$ & $5(5,5)$ & $5(5,7)$ & $5(4,5)$ & 0.409 \\
\hline Rhinitis (\%)† & $13(37.1)$ & $1(25)$ & $4(44.4)$ & $17(44.7)$ & 0.208 \\
\hline Anxiety† [24] & $5(0,7)$ & $2(0,5)$ & $0(0,11)$ & $4(0,6)$ & 0.473 \\
\hline Depressiont [25] & $3(0,7)$ & $3(0,7)$ & $0(0,7)$ & $1(0,5)$ & 0.771 \\
\hline Ex-smoker (\%)† & $16(43.2)$ & $3(75.0)$ & $6(66.7)$ & $13(34.2)$ & 0.154 \\
\hline Smoking indext & $0(0,6.9)$ & $12.4(2.4,33.8)$ & $1.0(0.0,32.5)$ & $0.0(0.0,19.5)$ & 0.323 \\
\hline Post-bronchodilator FEV1 (L) † & $2.33(2.08,3.13)$ & $0.67(0.67,1.61)$ & $2.27(1.64,2.92)$ & $2.42(1.38,3.04)$ & 0.538 \\
\hline Post-bronchodilatorFEV1/pred (\%)† & $87(70.8,97.7)$ & $29.3(27.65,68.9)$ & $81.4(57.6,99.15)$ & $90.8(54.1,100.4)$ & 0.634 \\
\hline Post-bronchodilator FVC (L) † & $3.74(3.11,4.48)$ & $1.9(1.71,2.61)$ & $3.44(3.07,3.78)$ & $3.67(2.39,4.18)$ & 0.892 \\
\hline Post-bronchodilator FVC/pred (\%)† & $106.67 \pm 24.46$ & $73.33 \pm 36.35$ & $94.2 \pm 24.95$ & $100.59 \pm 26.84$ & 0.633 \\
\hline FeNO (ppd) † & $42.4(32.65,131.5)^{\Delta}$ & $23(18,76)$ & $72.4(38,108.2)$ & $37(22.7,47.45) \S$ & 0.195 \\
\hline ICS/LABA, n (\%)† & $37(97.3)$ & $4(100)$ & $9(100)$ & $28(73.7)$ & 0.239 \\
\hline ICS dose $(\mu \mathrm{g}) \dagger$ & $400(400,500)$ & $450(400,500)$ & $400(325,500)$ & $500(400,800)$ & 0.319 \\
\hline \multicolumn{6}{|l|}{ Sputum Cell Count (median $(q 1, q 3))$} \\
\hline Total cells $\left(10^{6} / \mathrm{mL}\right)+$ & $3.6(1.8,5.4)$ & $3.0(0.75,7.55)$ & $2.9(1.8,3.6)$ & $2.9(1.8,5.4)$ & 0.812 \\
\hline Neutrophils $\left(10^{6} / \mathrm{mL}\right)+$ & $0.07(0.01,1.38) \#$ & $2(0.61,4.59) \stackrel{\Delta}{\S}$ & $1.83(1.32,2.65)^{\Delta \S}$ & $0.06(0.01,0.48)$ \#※ & $<0.001$ \\
\hline Neutrophils, \%, † & $4.0(1.2,10.0) \#^{\# ※}$ & $65.25(61.0,82.4)^{\Delta \S}$ & $70(63.3,73.4) \stackrel{\Delta}{\Delta}$ & $2.2(0.6,24.0))^{\# \circledast}$ & $<0.001$ \\
\hline Eosinophils $\left(10^{6} / \mathrm{mL}\right) \dagger$ & $0.82(0.21,1.37) \# \approx \Delta$ & $0.01(0,0.13)^{\S}$ & $0.12(0.09,0.22)^{\S}$ & $0(0,0.04)^{\S}$ & $<0.001$ \\
\hline Eosinophils, \%, † & $17.0(8.7,40.1){ }^{\# ※ \Delta}$ & $1.6(0.2,2.8)^{\S}$ & $4.9(3.3,13.1)^{\S}$ & $0.2(0,1.0)^{\S}$ & $<0.001$ \\
\hline Macrophages $\left(10^{6} / \mathrm{mL}\right)+$ & $1.55(0.31,3.51) \# ※ \Delta$ & $0.56(0.01,1.16)^{\S *}$ & $0.47(0.11,0.77)^{\S ※}$ & $1.91(0.56,4.52)^{\S \# ※}$ & $<0.001$ \\
\hline Macrophages, \%, † & $58.3(37.3,80.5))^{\# ※ \Delta}$ & $15.1(7.8,24.8)^{\S ※}$ & $21.3(11.4,28.0)^{\S ※}$ & $85.4(49.1,95.6)^{\S} \# ※$ & $<0.001$ \\
\hline Lymphocytes $\left(10^{6} / \mathrm{mL}\right) \dagger$ & $0.03(0,0.15)$ & $0.21(0.01,0.66)$ & $0(0,0.01)$ & $0.03(0,0.17)$ & 0.406 \\
\hline Lymphocytes, \%, † & $1.8(0.5,6.6)$ & $5.9(2.9,8.9)$ & $0(0,0.5)$ & $1.4(0.3,13.0)$ & 0.562 \\
\hline Columnar epithelial cells $\left(10^{6} / \mathrm{mL}\right) \dagger$ & $0.04(0,1.09)$ & $0.1(0.02,1.42)$ & $0(0,11.79)$ & $0.05(0.01,0.24)$ & 0.072 \\
\hline Columnar epithelial cells, \%, † & $1.4(0.5,3.0)^{\triangle}$ & $3.8(2.8,14.7)$ & $0(0,2.6)^{\Delta}$ & 3. $5(0.8,11.4)^{\S}$ & 0.017 \\
\hline
\end{tabular}

Note: Data are expressed as mean $\pm \mathrm{SD}$ or median (IQR). Data were analyzed using an ANOVA or Kruskal-Wallis test. $\dagger$ : adjusted for age. NA neutrophil type, MA mixed granulocyte type, $P A$ granulocyte-deficient type, $E A$ eosinophilic type. $p<0.05:{ }^{\#}$ vs.NA, ${ }^{*}$ vs. MA, ${ }^{\Delta}$ vs. PA, ${ }^{\S}$ vs. EA. BMI Body mass index, $A C T$ asthma control test, ACQ Asthma control questionnaire, AQLQ-S Asthma Quality of Life Questionnaire, FeNO Fractional exhaled nitric oxide, FVC Forced vital capacity, FEV1 Forced expiratory volume in $1 \mathrm{~s}$, ICS Inhaled corticosteroid, LABA long-acting $\beta 2$-agonists

concentration displayed a significant positive correlation with the severity of asthma symptoms [16]. However, another study showed the exact opposite result; this work found a decrease in circulating IL-35 levels in asthmatic patients, which increased the number of CD8+ T-cells that produce IL-4 [17]. In an OVAinduced asthma mouse model, adenovirus-mediated IL35 [41] or recombinant IL-35 [35] was used and inhibited the extent of AHR and allergic inflammation. Mice with glucocorticoid-sensitive eosinophilic airway inflammation induced by a HDM allergen-specific memory/effector Th2 cell line and treated by pVAX-IL-35 DNA via the intranasal route showed reduced allergen-specific airway inflammation compared to controls [15]. In addition, the intramuscular injection of pVAX-IL inhibited circulating allergen specificity and total IgE levels over a longer period of time. These differential findings may have been obtained due to the differences in asthma phenotypes.

Our results suggest that IL-35 may promote neutrophil exudation, which is consistent with previous results. The JM Zou team showed that the neutrophils in tumor tissues of IL-35 mice were significantly higher than those in tumor tissues of naive mice. Consistently, the 

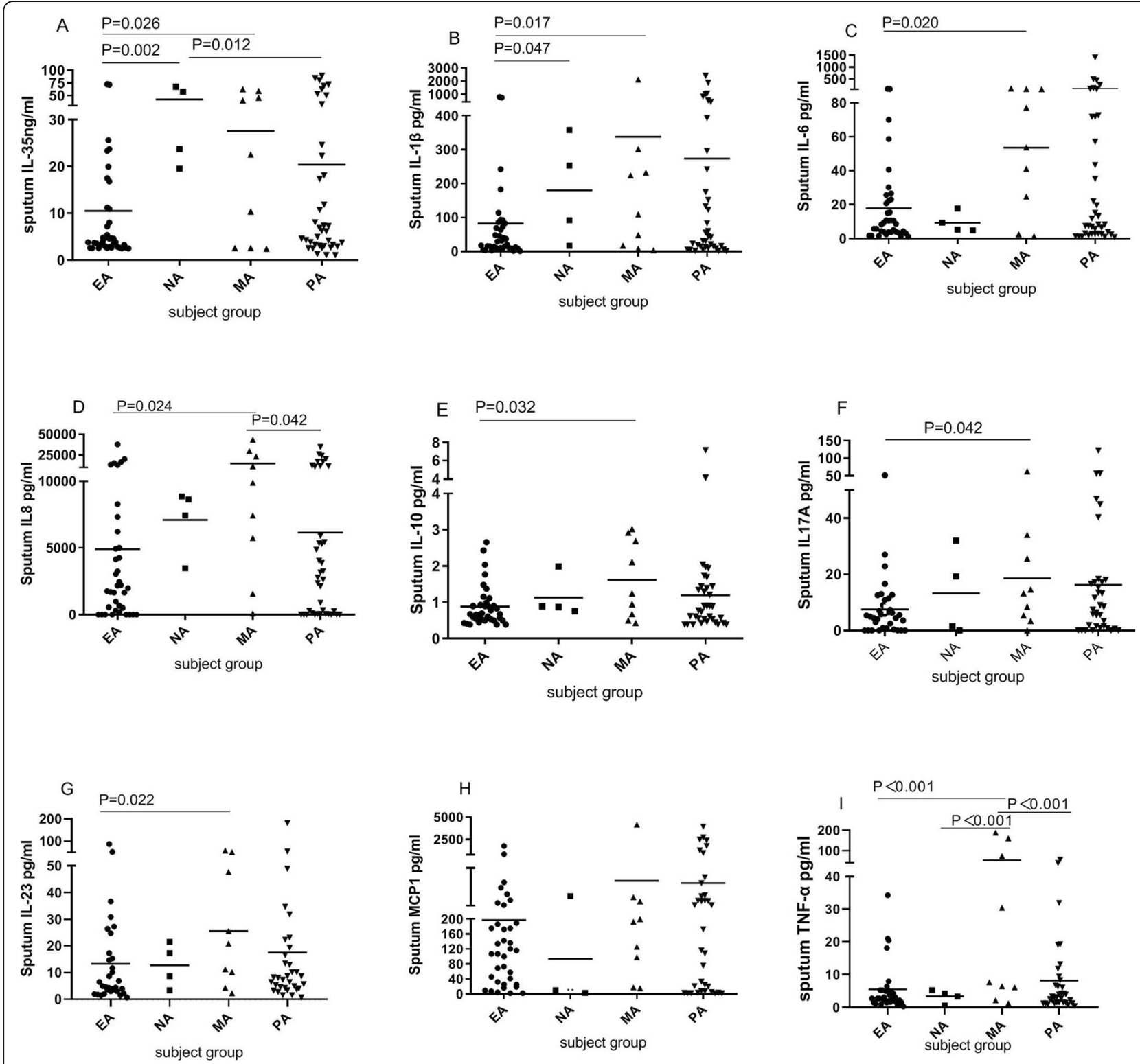

Fig. 1 Sputum concentrations of inflammatory mediators in the asthma inflammatory phenotypes

proportion of neutrophils in blood cells in IL-35 mice was significantly increased compared to that in control mice; thus, indicating that the in vivo expression of IL35 promotes the mobilization of neutrophils. Based on the expression of various chemokines to neutrophils in the tumor microenvironment, it was suggested that IL35 could promote the infiltration of neutrophils by increasing the circulating neutrophils [29]. The research by $\mathrm{K}$ Kanai et al. showed that airway delivery of IL-35 significantly reduced the number of eosinophils and the production of CCL11 and CCL24 in bronchoalveolar lavage fluid (BALF) from LPS-stimulated EBI3-deficient mice. On the other hand, airway delivery of anti-IL35 significantly increased the number of eosinophils in the BALF from LPS-stimulated WT mice. This study demonstrated that IL-35 inhibits LPS-induced airway eosinophilia, at least in part by reducing the local production of CCL11 and CCL24 [28].

In our study, there was a significant increase in IL-35 level in the sputum of patients with NA. The level of IL35 in the sputum of asthmatic patients displayed a significant negative correlation with lung function, and a significant positive correlation with IL-1 $\beta, 6$, and 8, which support the finding of upregulation of sputum IL35 in patients with more severe NA compared to other asthma types. This observation was further supported by 


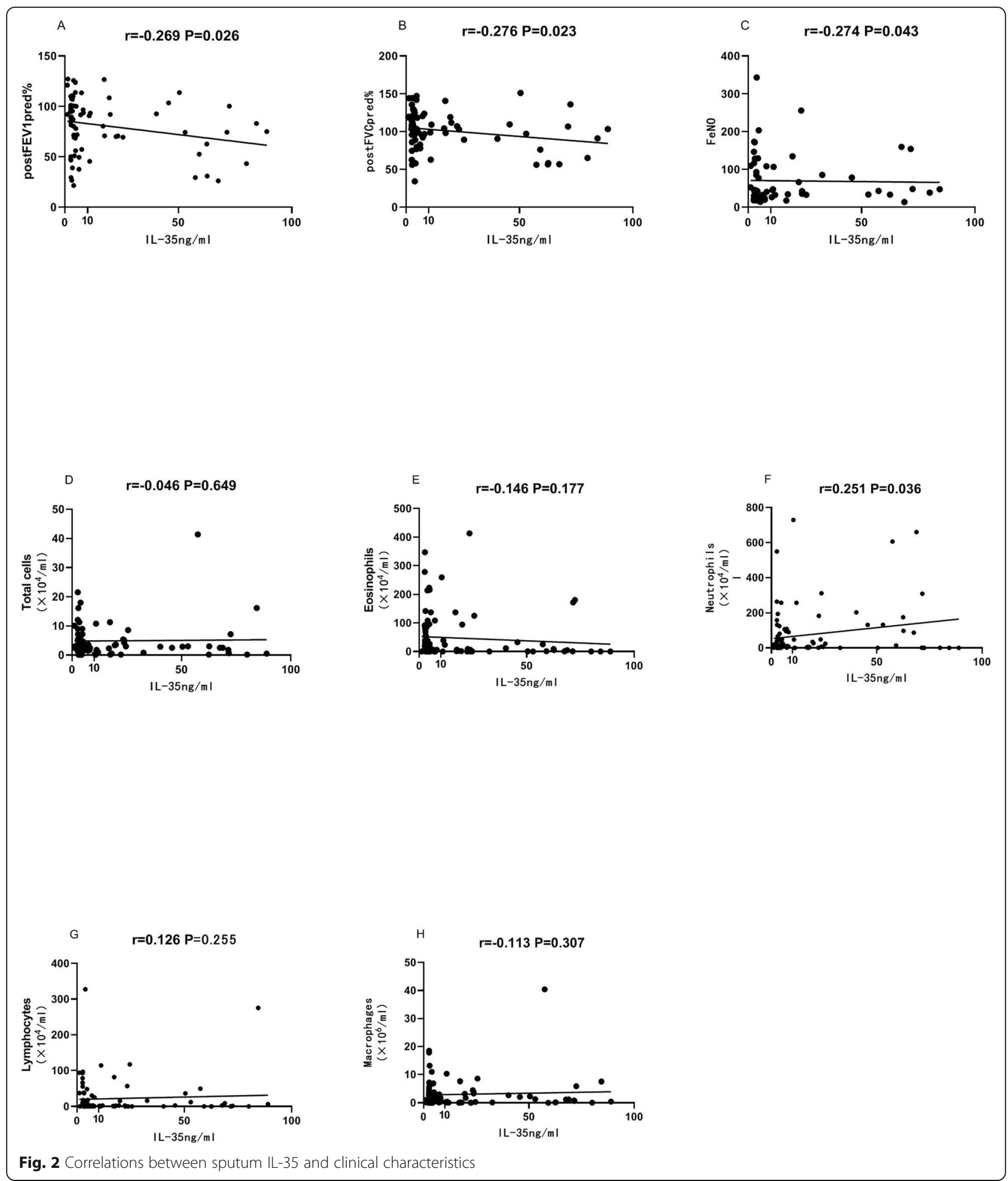

the GS Whitehead and $\mathrm{CH}$ Huang study, which found that upregulation of IL-35 was positively correlated with the disease severity score (DSS) $[15,42]$.

A study found that adenovirus-mediated IL-35 gene delivery can affect allergic airway inflammation and AHR in a mouse asthma model $[14,41,43]$. Based on our results, we suggest that a positive correlation between IL-35 and neutrophils may be associated with severe airway inflammation in asthma. These results may lead to the discovery of different pathophysiological mechanisms of IL-35 in NA and EA. 
Table 4 Analysis of mediators according to the ICS dose category

\begin{tabular}{|c|c|c|c|c|}
\hline Variable (Pg/ml) & Low ICS dose & Middle ICS dose & High ICS dose & $P$ value \\
\hline IL-35 (ng/ml) & $3.33(2.63,7.40)$ & $6.25(3.13,24.16)$ & $6.51(3.67,30.63)$ & NS \\
\hline $\mathrm{IL}-1 \beta(\mathrm{pg} / \mathrm{ml})$ & $27.28(6.31,234.25)$ & $37.53(12.7,109.23)$ & $76.57(7.88,547.4)$ & NS \\
\hline IL-6 (pg/ml) & $7.06(2.93,62.01)$ & $10.56(3.99,30.15)$ & $11.67(3.67,104.88)$ & NS \\
\hline IL-8 (pg/ml) & $2449(8,5891)$ & $3248(558,11,186)$ & $1861(54,9775)$ & NS \\
\hline IL-10 (pg/ml) & $0.74(0.51,1.25)$ & $0.83(0.52,1.58)$ & $0.78(0.53,1.22)$ & NS \\
\hline IL-17A (pg/ml) & $5.76(0.32,12.24)$ & $6.77(1.73,17.12)$ & $5.57(1.39,13.7)$ & NS \\
\hline IL-23 (pg/ml) & $6.43(3.57,19.78)$ & $10.11(3.57,24.93)$ & $4.89(2.19,10.11)$ & NS \\
\hline TNF-a (pg/ml) & $2.64(1.34,6.29)$ & $3.74(1.7,7.63)$ & $2.71(1.87,16.13)$ & NS \\
\hline MCP-1 (pg/ml) & $97.8(5.5,241.5)$ & $115.8(16.8,273.7)$ & $228.3(98.4,1062.1)$ & NS \\
\hline
\end{tabular}

Data are expressed as median (IQR). Data were analyzed using a Kruskal-Wallis test. ICS inhaled corticosteroid, NS non-significant, IL Interleukin, TNF Tumor necrosis factor, MCP monocyte chemoattractant protein

\section{Conclusion}

Il-35 may participate in the mechanism of the asthma phenotype through various mechanisms. However, more studies are needed to clearly determine the role of IL-35 in the different phenotypes of asthma and to evaluate possible new strategies for therapies based on the IL-35 characterization.

\section{Supplementary information}

Supplementary information accompanies this paper at https://doi.org/10 1186/s12931-020-01356-6.

Additional file 1: Supplementary Table 1. Values of correlation

between sputum inflammatory mediators in asthma patients

\section{Abbreviations}

IL: Interleukin; TNF: Tumor necrosis factor; ELISA: Enzyme-linked immunosorbant assay; BMI: Body mass index; AHR: Airway hyperresponsiveness; ACQ: Asthma control questionnaire; FeNO: Fractional exhaled nitric oxide; FEV1: Forced expiratory volume in $1 \mathrm{~s}$; FVC: Forced vital capacity; TCC: Total cell count; SD: Standard deviation; ANOVA: Analysis of variance; LSD: Least significant difference; IQR: Interquartile range; OR: Odd ratio; Cl: Confidence interval; ICS: Inhaled corticosteroid; COPD: Chronic obstructive pulmonary disease; NA: Neutrophilic asthma; EA: Eosinophilic asthma; PA: Paucigranulocytic asthma; MGA: Mixed granulocytic asthma

\section{Acknowledgements}

Not applicable.

\section{Authors' contributions}

GP contributed to the conception of the study. WL, RG and TX drafted the manuscript. All authors revised the manuscript critically and approved the final version.

\section{Funding}

This work was funded by the Jilin province development and reform commission plan (2019C047-7), Jilin province science and technology development plan, Jilin province medical and health personnel project and Jilin province health commission technology innovation plan (2018 J046). The design of the study and writing of the manuscript were in accordance with the rules of the funding body.

Availability of data and materials

All data generated or analyzed during this study are included in this article.
Ethics approval and consent to participate

This study was approved by the Ethical approval was received from the Ethics Committee of the Second Hospital of Jilin University (approval number: 2014-003). Informed consent was obtained from all patients before enrollment in this study.

\section{Consent for publication}

Not applicable.

\section{Competing interests}

The authors declare that they have no competing interests.

\section{Author details}

${ }^{1}$ Department of Respiratory and Critical Care Medicine, The Second Hospital of Jilin University, Changchun, Jilin 130041, China. ${ }^{2}$ Department of Medical Laboratory Technology, Beihua University, Jilin 132013, Jilin, China.

${ }^{3}$ Department of Respiratory, Xinqiao Hospital, Army Medical University (Third Military Medical University), Chongqing 400037, China.

Received: 17 August 2019 Accepted: 6 April 2020

Published online: 16 April 2020

\section{References}

1. Mortality GBD. Causes of death C: global, regional, and national life expectancy, all-cause mortality, and cause-specific mortality for 249 causes of death, 1980-2015: a systematic analysis for the global burden of disease study 2015. Lancet. 2016;388:1459-544.

2. Gao P, Gibson PG, Baines KJ, Yang IA, Upham JW, Reynolds PN, Hodge S, James $A L$, Jenkins $C$, Peters $M J$, et al. Anti-inflammatory deficiencies in neutrophilic asthma: reduced galectin-3 and IL-1RA/IL-1 beta. Respir Res. 2015;16:5.

3. Hamid Q, Tulic M. Immunobiology of asthma. Annu Rev Physiol. 2009;71: 489-507.

4. Perlikos F, Hillas G, Loukides S. Phenotyping and Endotyping asthma based on biomarkers. Curr Top Med Chem. 2016:16:1582-6.

5. Bruijnzeel PL, Uddin M, Koenderman L. Targeting neutrophilic inflammation in severe neutrophilic asthma: can we target the disease-relevant neutrophil phenotype? J Leukoc Biol. 2015;98:549-56.

6. Gibson PG. Inflammatory phenotypes in adult asthma: clinical applications. Clin Respir J. 2009;3:198-206.

7. Sousa AR, Marshall RP, Warnock LC, Bolton S, Hastie A, Symon F, Hargadon $B$, Marshall H, Richardson M, Brightling CE, et al. Responsiveness to oral prednisolone in severe asthma is related to the degree of eosinophilic airway inflammation. Clin Exp Allergy. 2017:47:890-9.

8. Pavord ID, Afzalnia S, Menzies-Gow A, Heaney LG. The current and future role of biomarkers in type 2 cytokine-mediated asthma management. Clin Exp Allergy. 2017;47:148-60.

9. Mims JW. Asthma: definitions and pathophysiology. Int Forum Allergy Rhinol. 2015;5(Suppl 1):S2-6.

10. Esteban-Gorgojo I, Antolin-Amerigo D, Dominguez-Ortega J, Quirce S. Noneosinophilic asthma: current perspectives. J Asthma Allergy. 2018;11:267-81. 
11. Trinchieri G. Interleukin-12 and the regulation of innate resistance and adaptive immunity. Nat Rev Immunol. 2003;3:133-46.

12. Collison LW, Delgoffe GM, Guy CS, Vignali KM, Chaturvedi V, Fairweather D, Satoskar AR, Garcia KC, Hunter CA, Drake CG, et al. The composition and signaling of the IL-35 receptor are unconventional. Nat Immunol. 2012;13: 290-9.

13. Tong H, Miyazaki Y, Yamazaki M, Hara H, Waldmann H, Hori S, Yoshida H. Exacerbation of delayed-type hypersensitivity responses in EBV-induced gene-3 (EBI-3)-deficient mice. Immunol Lett. 2010;128:108-15.

14. Liu JQ, Liu Z, Zhang X, Shi Y, Talebian F, Carl JW Jr, Yu C, Shi FD, Whitacre CC, Trgovcich J, Bai XF. Increased Th17 and regulatory T cell responses in EBV-induced gene 3-deficient mice lead to marginally enhanced development of autoimmune encephalomyelitis. J Immunol. 2012;188:3099-106.

15. Huang CH, Loo EX, Kuo IC, Soh GH, Goh DL, Lee BW, Chua KY. Airway inflammation and IgE production induced by dust mite allergen-specific memory/effector Th2 cell line can be effectively attenuated by IL-35. J Immunol. 2011;187:462-71.

16. Wong CK, Leung TF, Chu IM, Dong J, Lam YY, Lam CW. Aberrant expression of regulatory cytokine IL-35 and pattern recognition receptor NOD2 in patients with allergic asthma. Inflammation. 2015:38:348-60.

17. Wang W, Li P, Yang J. Decreased circulating Interleukin-35 levels are related to Interleukin-4-producing CD8+ T cells in patients with allergic asthma. Iran J Allergy Asthma Immunol. 2015;14:379-85.

18. Standards for the diagnosis and care of patients with chronic obstructive pulmonary disease (COPD) and asthma. This official statement of the American Thoracic Society was adopted by the ATS Board of Directors, November 1986. Am Rev Respir Dis. 1987;136:225-44.

19. Gibson PG, Wlodarczyk JW, Hensley MJ, Gleeson M, Henry RL, Cripps AW, Clancy RL. Epidemiological association of airway inflammation with asthma symptoms and airway hyperresponsiveness in childhood. Am J Respir Crit Care Med. 1998;158:36-41.

20. Baines KJ, Simpson JL, Wood LG, Scott RJ, Gibson PG. Systemic upregulation of neutrophil alpha-defensins and serine proteases in neutrophilic asthma. Thorax. 2011;66:942-7.

21. Juniper EF, O'Byrne PM, Guyatt GH, Ferrie PJ, King DR. Development and validation of a questionnaire to measure asthma control. Eur Respir J. 1999; 14:902-7.

22. Nathan RA, Sorkness CA, Kosinski M, Schatz M, Li JT, Marcus P, Murray JJ, Pendergraft TB. Development of the asthma control test: a survey for assessing asthma control. J Allergy Clin Immunol. 2004;113:59-65.

23. Juniper EF, Guyatt GH, Epstein RS, Ferrie PJ, Jaeschke R, Hiller TK. Evaluation of impairment of health related quality of life in asthma: development of a questionnaire for use in clinical trials. Thorax. 1992:47:76-83.

24. Zung WW. A rating instrument for anxiety disorders. Psychosomatics. 1971, 12:371-9.

25. Zung WW. A self-rating depression scale. Arch Gen Psychiatry. 1965;12:6370 .

26. Hoppe S, Keel MJ. Pedicle screw augmentation in osteoporotic spine: indications, limitations and technical aspects. Eur J Trauma Emerg Surg. 2017:43:3-8

27. Mansour Al, Abd Almonaem ER, Behairy OG, Gouda TM. Predictive value of IL-35 and IL-17 in diagnosis of childhood asthma. Scand J Clin Lab Invest. 2017;77:373-8

28. Kanai K, Park AM, Yoshida H, Tsunoda I, Yoshie O. IL-35 suppresses lipopolysaccharide-induced airway eosinophilia in EBI3-deficient mice. J Immunol. 2017;198:119-27.

29. Zou JM, Qin J, Li YC, Wang Y, Li D, Shu Y, Luo C, Wang SS, Chi G, Guo F, et al. IL-35 induces N2 phenotype of neutrophils to promote tumor growth. Oncotarget. 2017;8:33501-14

30. Filkova M, Vernerova Z, Hulejova H, Prajzlerova K, Veigl D, Pavelka K, Vencovsky J, Senolt L. Pro-inflammatory effects of interleukin-35 in rheumatoid arthritis. Cytokine. 2015;73:36-43.

31. Thiolat A, Denys A, Petit M, Biton J, Lemeiter D, Herve R, Lutomski D, Boissier MC, Bessis N. Interleukin-35 gene therapy exacerbates experimental rheumatoid arthritis in mice. Cytokine. 2014;69:87-93.

32. Kuo J, Nardelli DT, Warner TF, Callister SM, Schell RF. Interleukin-35 enhances Lyme arthritis in Borrelia-vaccinated and -infected mice. Clin Vaccine Immunol. 2011;18:1125-32.
33. Teng DK, Liu Y, LV YF, Wang L, Zhang W, Wang JP, Li Y. Elevated interleukin35 suppresses liver inflammation by regulation of T helper 17 cells in acute hepatitis B virus infection. Int Immunopharmacol. 2019;70:252-9.

34. Pan X, Xu K, Li Y, Wang X, Peng X, Li M, Li Y. Interleukin-35 expression protects against cigarette smoke-induced lung inflammation in mice. Biomed Pharmacother. 2019;110:727-32.

35. Dong J, Wong CK, Cai Z, Jiao D, Chu M, Lam CW. Amelioration of allergic airway inflammation in mice by regulatory IL-35 through dampening inflammatory dendritic cells. Allergy. 2015;70:921-32.

36. Yu W, Ge M, Lu S, Shi J, Li X, Zhang J, Wang M, Huang J, Shao Y, Huang Z, et al. Anti-inflammatory effects of interleukin-35 in acquired aplastic anemia. Cytokine. 2015;76:409-16.

37. Huang Y, Lin YZ, Shi Y, Ji QW. IL-35: a potential target for the treatment of atherosclerosis. Pharmazie. 2013;68:793-5.

38. Niedbala W, Wei XQ, Cai B, Hueber AJ, Leung BP, McInnes IB, Liew FY. IL-35 is a novel cytokine with therapeutic effects against collagen-induced arthritis through the expansion of regulatory T cells and suppression of Th17 cells. Eur J Immunol. 2007;37:3021-9.

39. Wirtz S, Billmeier U, McHedlidze T, Blumberg RS, Neurath MF. Interleukin-35 mediates mucosal immune responses that protect against T-cell-dependent colitis. Gastroenterology. 2011;141:1875-86.

40. Kochetkova I, Golden S, Holderness K, Callis G, Pascual DW. IL-35 stimulation of CD39+ regulatory $T$ cells confers protection against collagen II-induced arthritis via the production of IL-10. J Immunol. 2010;184:7144-53.

41. Li Y, Pan X, Peng X, Li S, Zhou Y, Zheng X, Li M. Adenovirus-mediated interleukin-35 gene transfer suppresses allergic airway inflammation in a murine model of asthma. Inflamm Res. 2015;64:767-74.

42. Whitehead GS, Wilson RH, Nakano K, Burch LH, Nakano H, Cook DN: IL-35 production by inducible costimulator (ICOS)-positive regulatory $\mathrm{T}$ cells reverses established IL-17-dependent allergic airways disease.J Allergy Clin Immunol2012, 129:207-215 e201-205.

43. Niedbala W, Wei XQ, Cai B, Hueber AJ, Leung BP, Mclnnes IB, Liew FY. IL-35 is a novel cytokine with therapeutic effects against collagen-induced arthritis through the expansion of regulatory $T$ cells and suppression of Th17 cells. Eur J Immunol. 2007;37:3021-9..

\section{Publisher's Note}

Springer Nature remains neutral with regard to jurisdictional claims in published maps and institutional affiliations.

Ready to submit your research? Choose BMC and benefit from:

- fast, convenient online submission

- thorough peer review by experienced researchers in your field

- rapid publication on acceptance

- support for research data, including large and complex data types

- gold Open Access which fosters wider collaboration and increased citations

- maximum visibility for your research: over $100 \mathrm{M}$ website views per year

At $\mathrm{BMC}$, research is always in progress.

Learn more biomedcentral.com/submissions 